\title{
0 que dizem a legislação e o controle social em saúde sobre a formação de recursos humanos e o papel dos gestores públicos, no Brasil
}

\author{
What says the law and the "social control" in health \\ on the production human resources and the role \\ of public managers, in Brazil
}

Ricardo Burg Ceccim 1 Teresa Borgert Armani 2 Cristianne Famer Rocha 3

\footnotetext{
1 Universidade Federal do Rio Grande do Sul e Escola de Saúde Pública do Rio Grande do Sul. Av. I piranga 6311, Partenon, 90610-001, Porto Alegre RS. esp@saude.rs.gov.br 2 Escola de Saúde Pública do Rio Grande do Sul.

3 Universidade Estadual do Rio Grande do Sul e Universidade Federal do Rio Grande do Sul.
}

Resumo 0 artigo apresenta as responsabilidades previstas em lei e imputadas pela sociedade ao exercício da condução legal elegítima do setor saúde, permitindo que se possa, no tocante à formação e desenvolvimento dos recursos humanos em saúde, avaliar o atendimento, omissões e descumprimento daquilo que já foi pensado, planejado e formulado para a educação de profi ssionais de saúde no Brasil pelo próprio Sistema Ú nico de Saúde (SUS).

Palavras-chave Recursos humanos em saúde, Formação e desenvolvimento de pessoal de saúde, Educação dos profissionais de saúde, Trabalhadores no Sistema Ú nico de Saúde 
Esteartigo foi montado com uma estrutura bastante singular em busca da identificação das inter secções G estão em Saú de e Formação de Pessoal para o SU S e se faz pela compilação de informações constantes na legislação do SUS (o que está consolidado legalmente) e nos fóruns participatórios em saúde ( o que está legitimado ou pedelegitimidade na sociedade). A singularidade do artigo está em seu esforço dialógico: exposição dos prolegômenos, engendramento da interlocução com a lei e o controle social e o fechamento, que conformam uma apresentação em prólogo, diálogo e epílogo.

\section{Prólogo}

Sem a preocupação de transcrição literal, uma vez que são recortes de textos cuja compreensão supõe leitura completa dos documentos de origem (compreender sua inscrição contextual), pinçamos do texto legal de ordenamento do Sistema de Saúde no Brasil e dos relatórios da principal instância nacional de manifestação dos interesses sociais e da cidadania na área da saúde, que é a Conferência Nacional de Saúde (conforme lei federal no 8.142/90), aqueles aspectos que apontam as responsabilidades da gestão do Sistema Único de Saúde (SUS) para com o desenvolvimento e a formação de recursos humanos em saúde.

D estacamos que o desenvolvimento se refere à educação de profissionais durante sua experiência de emprego no setor e aparece nos vários documentos citados sob diferentes designações, tais como educação contínua ou continuada, educação permanente, reciclagem, capacitação, aperfeiçoamento, treinamento e motivação; enquanto a formação se refere à educação formal que gera uma certificação/habilitação profissional específica, podendo estar voltada ao pessoal inserido no serviço ou não, aparecendo, geralmente, sob esta mesma designação ou sob a identificação dos programas e cursos de educação profissional, educação superior e educação pós- graduada.

Este recorte se deveu à busca da identificação de responsabilidades previstas em lei e imputadas pela sociedade ao exercício da condução legal e legítima do setor saúde, permitindo que se possa, neste particular, avaliar o atendimento, omissões e descumprimento daquilo que já foi pensado, planejado eformulado para a educação de profissionais de saúde no Brasil pelo próprio Sistema Ú nico de Saúde.
Em cada recorte tecemos breves comentários que permitem enfatizar as determinações legais e a participação social direta em comprometer os gestores do SU S com a educação dos recursos humanos em saúde.

\section{Diálogo}

\section{1 - Constituição Nacional de 1988}

Artigo 200: Ao Sistema Ú nico de Saúde compete, além de outras atribuições, nos termos da Lei :

III - ordenar a formação de Recursos Humanos na área da saúde;

V - incrementar em sua área de atuação o desenvolvimento científico e tecnológico.

N ote-se que aparece, tanto a ordenação da formação de Recursos Humanos quanto o desenvolvimento científico e tecnológico, por conseguinte, tanto uma responsabilidade para com a formação de pessoal de saúde de modo geral, quanto para a produção específica de conhecimento e tecnologia no âmbito do próprio Sistema. Ao conceber a área de formação como a ação educativa de qualificação de pessoal e a ação investigativa da pesquisa e inovação, a lei prevê que os órgãos gestores do SUS estruturem mecanismos de atuação educacional, que dêem conta de ambas as funções.

\section{2 - Lei Orgânica da Saúde de 1990}

Artigo 6o: Estão incluídas no campo de atuação do SU S:

III - a ordenação da formação de recursos humanos na área da saúde;

$X$ - o incremento, em sua área de atuação, do desenvolvimento científico e tecnológico.

Artigo 14: D everão ser criadas Comissões Permanentes de integração entre os serviços de saúde e as instituições de ensi no profissional e superior.

Parágrafo único: Cada uma dessas Comissões terá por finalidade propor prioridades, métodos e estratégias para a formação e educação continuada dos recursos humanos do Sistema Ú nico de Saúde na esfera correspondente, assim como em relação à pesquisa e à cooperação técnica entre essas instituições.

Na efetiva existência dessas Comissões, toca pensar que as mesmas devessem suceder a estrutura dos Pólos de Capacitação em Saúde da Família, uma vez que são mais abrangen- 
tes e podem absorver as demais frentes de capacitação requeridas pelo SUS, superando a tradicional e tão criticada fragmentação/segmentação da formação em saúde e que hoje ocorre entre Saúde da Família, Vigilância Sanitária, Vigilância Epidemiológica, Atenção Integrada às Doenças Prevalentes na I nfância, Atenção às Urgências e Emergências, Atenção à Gestação de Risco, entre outras.

Artigo 15: A União, os Estados, o Distrito Federal e os M unicípios exercerão, em seu âmbito administrativo, as seguintes atribuições:

IX - participação na formulação e na execução da política de formação e desenvolvimento de recursos humanos para a saúde;

XIX - realizar pesquisas e estudos na área da saúde.

A ação educacional como atribuição dos órgãos de gestão do SU S fica explicitada com as demarcações deste Artigo: formulação e execução da política de formação e desenvolvimento (formulação e execução de programas que envolvam tanto a certificação/habilitação profissional, quanto a educação continuada) de recursos humanos para a saúde; realização de pesquisas e de estudos na área da saúde ( produção de conhecimentos, informações e atualização técnico-profissional, por suposto).

Artigo 27: A política de recursos humanos na área da saúde será formalizada e executada articuladamente pelas diferentes esferas de governo, em cumprimento dos seguintes objetivos:

I - organização de um sistema de formação de recursos humanos em todos os níveis de ensino, inclusive de pós- graduação, além da elaboração de programas de permanente aperfeiçoamento de pessoal;

Parágrafo único: Os serviços públicos queintegram o SU S constituem campo de prática para o ensino e pesquisa, mediante normas específi cas elaboradas conjuntamente com o si stema educacional.

Além de reafirmar que os órgãos gestores devem formalizar e executar uma política de recursos humanos em que um de seus objetivos seja a organização de um sistema de formação ( todos os níveis, inclusive pós-graduação, além de programas de aperfeiçoamento permanente), o Artigo coloca os serviços de saúde como campos para o ensino e a pesquisa, logo, locais de ensino-aprendizagem que expressam a indissociabilidade dos papéis de gestão e formação no âmbito direto do SUS.

Artigo 30: As especializações na forma de treinamento em serviço sob supervisão serão re- gulamentadas por Comissão Nacional, [insti tuída junto ao Conselho Nacional de Saúde,] garantida a participação das entidades profissionais correspondentes.

A referência aos programas de residência coloca- os sob o domínio do Consel ho Nacional de Saúde, à semelhança da Comissão Nacional de Ética em Pesquisa, que já regulamentou sua interação com comitês por serviço ou por base territorial (estaduais, por exemplo), assegurando sua inserção ético-política à gestão do SU S.

\section{3 - VIII Conferência Nacional de Saúde}

(marco para a introdução do Sistema

Ú nico de Saúde na Constituição Nacional, cuja chamada foi a "Reformulação

do Sistema Nacional de Saúde"), 1986.

Para a reformulação do Sistema Nacional de Saúde, tema central da Conferência, foram sugeridos os seguintes princípios relacionados com a política de recursos humanos:

1) o novo Sistema deverá reger-se pelo princípio da capacitação e reciclagem permanentes de seus Recursos H umanos;

2) a formação dos profissionais de saúde deve estar integrada ao sistema regionalizado e hierarquizado de atenção à saúde;

3) os currículos da área da saúde deverão ser integrados por conhecimentos das práticas terapêuticas alternativas.

Aparecem, a partir da demarcação da reforma sanitária ( reformulação do Sistema Nacional de Saúde) , a edu cação permanente e a formação dos profissionais de saúde, destacando-se a adequação da educação dos profissionais à regi onalização e à hierarquização do sistema de saúde.

\section{4 - IX Conferência Nacional de Saúde (primeira Conferência após a criação do SUS na Constituição Nacional, sua chamada foi "M unicipalização é o Caminho"), 1992.}

Para a implementação do SU S, com relação à área de Recursos Humanos, a Conferência entendeu como necessário:

1) assegurar uma Política de Formação e Capacitação de Recursos Humanos que se articule com os órgãos formadores;

2) promover a imediata regulamentação do Art. 200, Inciso III, da Constituição Nacional que atribui ao SU S a tarefa de ordenar a formação de recursos humanos; 
3) garantir escolas de formação de trabalhadores de saúde nas Secretarias de Saúde ou através de articulação com Secretarias de Educação, Universidades e outras instituiç̧ões públicas de ensino superior;

4) assegurar que as Secretarias M unicipais e Estaduais de Saúde destinem recursos orçamentários para a capacitação e treinamento dos seus quadros de pessoal e criação de núcleos de recursos humanos, com atividades de administração e desenvolvimento;

5) garantir a manutenção de programas de re sidência médica pelas unidades do SU S e ampliação do número de vagas, contemplando também as demais categorias profissionais da área da saúde. Os atuais programas de residência mé dica e de outras categorias profissionais nos hospitais do Inamps não deverão sofrer descontinuidade.

A primeira Conferência realizada após a aprovação da Lei Orgânica da Saúde sugere que, para implementar o SUS, énecessário assegurar políticas para a capacitação (educação continuada/desenvolvimento) e para a formação (certificação/habilitação profissional).

Enfatiza-se a reivindicação da regulamentação do artigo 200 da Constituição N acional, quanto à ordenação de recursos humanos, 0 que será retomado nas demais Conferências, lembrando que este aspecto já correspondera ao artigo 6o da Lei Orgânica da Saúde - LOS.

Esta Conferência reivindicou, também, que os gestores garantissem escolas de formação de trabalhadores em saúde em suas estruturas gerenciais ou em articulação, principalmente com universidades públicas.

Surge, a partir desta Conferência, e se repetirá nas seguintes, que os gestores devam garantir recursos orçamentários para a educação dos profissionais, bem como devam criar núcleos de desenvolvimento de trabalhadores junto à gestão de recursos humanos. 0 desenvolvimento de trabal hadores, que deve estar inserido na gestão de recursos humanos, se re fere aos programas e ações geridos em cada esfera de contratação de servidores para a sua atual ização ea modernização de processos de trabal ho, como para a adesão e motivação para o trabal ho. Volta-se para o gerenciamento do próprio trabalho, não se configurando como o trabalho de escola, mas de educação pelo trabalho.

A IX Conferência destacou ainda a importância da manutenção dos programas de residência, sua ampliação para o conjunto das pro- fissões da saúde e a não redução de vagas entre os programas de residência médica ou de outras profissões em funcionamento nos serviços do Inamps, no processo de transferência para o SUS.

\section{5 - X Conferência Nacional de Saúde}

(sua chamada foi "Onde dá SUS, dá certo!"), 1996.

Quanto aos Recursos H umanos em Saúde, no que se refere à administração dos trabal hadores de saúde, aparece a qualificação dos trabalhadores em saúde, assim proposta:

1) o M inistério da Saúde e as Secretarias Estaduais e M unicipais de Saúde devem promover programas permanentes de capacitação, formação, educação continuada, reciclagem e motivação das Equipes de Trabalhadores em Saúde;

2) as Secretarias Estaduais e M unici pais de Saúde das Capitais devem implantar e manter técnica e financeiramente Centros Formadores de Trabalhadores em Saúde, autônomos, com atuação integrada com os Consel hos Estaduais e M unici pais de Saú de e com as Secretarias de Educação e U niversidades;

3) o M inistério da Saúde e as Secretarias Estaduais e M uni ci pais de Saúde devem estimular e fomentar a capacitação em gerência de serviços para os Secretários e D irigentes de Saúde, em parceria com o Conass, Conasems, Cosems, universidades e N úcleos de Saúde Col etiva;

4) o M inistério da Saúde e as Secretarias Estaduais de Saúde devem manter assessoria permanente aos M unicípios para a realização de programas permanentes de capacitação, formação, educação continuada, reciclagem e motivação de trabalhadores em saúde.

Quanto à formação e desenvolvimento de Recursos Humanos em Saúde foi deliberado que:

1) o M inistério da Saúde deve apresentar, após ampla discussão com as entidades representativas da área, um Plano de O rdenamento da $\mathrm{Ca}$ pacitação, Formação, Educação Continuada e Reciclagem de Recursos Humanos em Saúde, para deliberação do Consel ho N acional de Saúde, que seja articulado nacionalmente, inclusive com previsão de repasses financei ros específicos para essas atividades, baseado nos seguintes princípios:

- criação de Comissões Permanentes para integração entre os Consel hos de Saúde, os serviços de saúde e as Instituições de Ensino Fundamental e Superior, para deliberar sobre a capacita- 
ção, formação, educação continuada e reci clagem dos Recursos Humanos em Saúde, a partir da ótica do SUS:

- fortalecimento dos vínculos com Universidades, promovendo articulações intersetoriais, para que a formação dos profissionais seja modificada, capacitando-os para atuar na Aten ção Integral à Saúde, individual e coletiva;

- revisão imediata dos currículos mínimos dos cursos de nível superior, com a participação dos gestores do SU S e Consel hos de Saúde, adequando-os às realidades locais e regionais, aos avanços tecnológicos, às necessidades epidemi ológicas e às demandas quantitativas e qualitativas do Sistema Ú nico de Saúde;

- estímulo à utilização das unidades e serviços do SU S como espaço prioritário para a formação de trabalhadores em saúde (sistema de saúde-escola), com a supervi são das unidades de ensino e de serviço, garantindo um intercâmbio qualificado entre essas instituições e a formação de profissionais com perfil mais compatível com o SUS;

- fomento à integração das instituições de ensino superior, particularmente as universidades públicas (federais e estaduais), para a execução de programas de formação e desenvolvimento de trabalhadores em saúde de todos os níveis de escolaridade;

- estímulo à criação de Escolas de Saúde Pública em todos os Estados da União;

- criação de novos cursos de nível médio e superior para a área da saúde de acordo com as necessidades do SU S, identificadas a partir de critérios epidemiológicos e da manifestação dos Conselhos de Saúde;

- organização de programas de ajuda financeira, condicionada à prestação de serviços em Unidades e Serviços de Saúde públicos por tempo equivalente aos recursos investidos, para estudantes dos cursos de interesse para o SUS;

- reestruturação dos Programas de Residência M édica e Estágios, com vistas a sua adequação às necessidades do SU S;

- fomento à Educação Continuada, através do aumento de vagas para a residência médica ea criação de programas de residência e estágios de enfermagem, psicologia, nutrição, farmácia, serviço social, fonoaudiologia, fisioterapia, terapia ocupacional e todas as profissões de nível superior ligadas à saúde;

- qualificação dos cursos profissionalizantes de nível médio para a área da saúde, com fiscalização rigorosa e fechamento dos que não têm condições de funcionamento.
2) os M inistérios da Saúde e da Educação devem estimular a implementação de Programas de Especialização em Saúde Pública eem Gerenciamento de Serviços de Saúde desenvolvidos pelas universidades em parcerias com os governos Estaduais e/ ou M unicipais;

3) os Gestores do SU S e os órgãos de fomento à pesquisa devem apoiar, valorizar e participar de projetos de avaliação das instituições formadoras de recursos humanos em saúde, como os da Cinaem e da Rede Unida que buscam a integração escola-comunidade ea formação humanística dos futuros profissionais.

A X Conferência Nacional de Saúde propôs que as Secretarias Estaduais de Saúde e as Secretarias M unicipais de Saúde das Capitais devessem implantar e manter técnica e financeiramente escolas de formação, com autonomia e integradas aos respectivos Conselhos de Saúde, bem como às respectivas Secretarias de Educação e às universidades, podendo-se supor que privilegiadamente às Universidades Estaduais. 0 próprio M inistério da Saúde mantém uma Escola Nacional de Saúde Pública e um Centro de Saúde-Escola no Rio Janeiro.

A Conferência destacou a importância da ligação da formação dos recursos humanos em saúde afeta aos N úcleos de Estudos e Pesquisas em Saúde Coletiva com as instâncias de representação dos gestores de saúde como os Consel hos N acionais de Secretários Estaduais e de Secretários M unicipais de Saúde - Conass e Conasems e Consel hos Estaduais de Secretários M unicipais de Saúde - Cosems, denotando o esforço de constituir uma política de desenvolvimento e formação que diga respeito às universidades e aos gestores em saúde e venha fortalecer o Sistema Ú nico de Saúde. Esta integração ficou proposta inclusive para o desafio de formular programas permanentes de capacitação para os municípios.

Nesta Conferência, não só foi novamente solicitada a regulamentação do artigo $200 \mathrm{da}$ Constituição Nacional ou artigo 6o da Lei Orgânica da Saúde, como também que o M inistério da Saúde apresentasse um Plano de Ordenamento da Capacitação, Formação, Educação Continuada e Reciclagem dos Recursos H umanos em Saúde. Para a apresentação deste Plano, que chegou a contar com a pressão da sugestão de um prazo máximo de 180 dias da publicação do relatório da mesma, foram imputados princípios balizadores, entre eles a criação de Comissões Permanentes como as já previstas no artigo 14 da Lei Orgânica da Saú- 
de e o estímulo à criação de Escolas de Saúde Pública em todos os estados da federação.

Atualmente, existem Escolas de Saúde Pública no Rio Grande do Sul (esta Escola estará oferecendo curso de graduação a partir de 2001, pela criação da Universidade Estadual do Rio Grande do Sul), em Minas Gerais, no Ceará, em Pernambuco, no M ato Grosso e no $M$ ato Grosso do Sul com perfis muito semeIhantes, mais a Escola de Saúde Pública do Paraná, que não oferece cursos regulares de formação/habilitação profissional, apenas educação continuada. Em São Paulo, há a Faculdade de Saúde Pública, da Universidade Estadual de São Paulo (USP), uma Escola Estadual no sentido amplo, mas que está integrada à estrutura de uma universidade de grande porte, oferece curso de graduação (nutrição) e possui um programa consolidado de pós-graduação stricto sensu. N essa lógica, seria o caso de considerar, no Rio de Janeiro, o Instituto de M edicina Social da Universidade Estadual do Rio deJaneiro (IM S/UERJ) um outro centro estadual formador de recursos humanos para a saúde pública, já que também possui um programa consolidado de stricto sensu, hoje oferecendo um mestrado profissionalizante em Saúde Coletiva, e registra a história de ter conduzido um importante Programa de Residência em M edicina Preventiva e Social. A Escola N acional de Saúde Pública, ligada à Fundação O swaldo Cruz (EN SP/Fiocruz), do M inistério da Saúde, tem a mesma missão das escolas citadas, mas pertence à esfera federal. Esta escola está no Rio de Janeiro e conta com programa consolidado de pós- graduação stricto sensu, oferecen do também programa de mestrado profissionalizante.

Junto ao governo estadual de Santa Catarina, há a Escola de Formação em Saúde; do Espírito Santo, o Instituto Estadual de Saúde Pública; e da Bahia, a Escola de Formação Técnica em Saúde, todas voltadas para a educação profissional do pessoal do nível médio. Em Goiás e em Alagoas, bem como no Rio Grande do Norte e na Paraíba existem os Centros de Formação de Recursos Humanos para a Saúde, também orientados exclusivamente para o ensino técnico (escolaridade fundamental, ensino de qualificação básica, ensino de habilitação profissional e ensino técnico especializado), integrando a Rede de Escolas Técnicas do SU S (RET-SUS).

Foi estimado pela $X$ Conferência que haveria a necessidade, a ser aprofundada junto ao controle social, da criação de novos cursos na área da saúde, tanto de nível médio, quanto superior, conforme documentado no relatório. N essa Conferência, os Programas de Residência retornaram com a recomendação de quesejam revisados para adequação ao SUS, tenham suas vagas ampliadas e sejam dimensionados para todas as profissões de nível superior ligadas à saúde.

Foi proposta a priorização da implantação de Programas de Especialização em Saúde Pública e em Gerenciamento de Serviços de Saúde em parceria de universidades, governos federal, estaduais e municipais, o que tem sido observado apenas recentemente, passados quase dez anos da IX Conferência. De igual importância, surgiu a proposição de apoio aos sistemas de avaliação do ensino que valorizem a integração escola-comunidade e a formação humanística.

Cabe destacar que a integração en sino-serviço foi recuperada com a inclusão da "comunidade", a partir da importância que se passou a dar ao controle social, permitindo que falemos em integração ensino-serviço-controle social.

Além dos projetos citados, vem-se debatendo no Brasil, por meio da Comissão Interinstitucional Nacional de Avaliação do Ensino M édico (Cinaem), sistemas de avaliação institucional no ensino de graduação; por meio da Rede Unida de Desenvolvimento dos Recursos Humanos em Saúde (Rede Unida), sistemas de acompanhamento institucional de projetos de mudança curricular e integração com a sociedade e, por meio da Fundação Oswaldo Cruz e Associação Brasileira de PósGraduação em Saúde Coletiva (Abrasco), o Projeto Nacional de Acreditação Pedagógica da Formação de Recursos Humanos em Saúde Pública, projeto que prevê a avaliação sob sistema de acompanhamento institucional e com projeto col etivo de mel horia da qualidade educacional da pós-graduação lato sensu na área da saúde pública/saúde coletiva.

O Instituto de M edicina Social da U niversidade Estadual do Rio de Janeiro está elaborando projeto nacional de aval iação das capacitações de gestores munici pais de saúde, com consulta aos vários segmentos de formação e gestão, que poderá se tornar uma nova referência de avaliação que considere a integração ensino-serviço-controle social. 


\section{6 - XI Conferência Nacional de Saúde}

(sua chamada foi "Efetivando o SU S:

qualidade e humanização na atenção

à saúde, com controle social”) , 2000.

Foram aprovadas as seguintes proposições quanto ao Controle Social:

1) articular a academia, os serviços de saúde, os Centros de Formação de Recursos Humanos das Secretarias de Saúde e os Pólos de Educação em Saúde para disponibilizar, periodicamente, cursos de formação para conselheiros de saúde e usuários do SU S em geral, com inclusão de temas gerais (princípios do SUS, seu papel na atenção à saúde) e específicos (orçamento, legisIação, controle e avaliação, contratos e convênios, planejamento e programação de serviços, sistema de informação, as $\mathrm{N}$ ormas $\mathrm{O}$ peracionais Básicas do SUS, financiamento, encaminhamento de questões de caráter legal junto ao $\mathrm{M}$ inistério Público...), garantindo a emergência de agentes sociais com formação crítica (política, ideológica e sociológica) no sentido de sua instituição como sujeitos da transformaç̧ão da ideologia hegemônica;

2) capacitar a Promotoria de Justiça, por intermédio dos promotores da área da cidadania; 3) promover a formação dos membros do $\mathrm{M} \mathrm{i-}$ nistério Público sobre as questões relacionadas à saúde pública e os princípios e diretrizes legais dos SUS, enfatizando a legitimidade e representatividade dos Consel hos de Saúde na deliberação da política de saúde em cada esfera de governo.

Quanto ao fortalecimento dos princípios do SU S, seu caráter público, a integralidade, a eqüidade e a humanização, sugeriu-se que: 1) os novos trabalhadores do setor público de saúde deverão ter formação adequada para 0 novo modelo de atenção à saúde preconizado e aos antigos em atuação na rede deve ser assegurado um programa de educação continuada através de Escolas Técnicas e de Escolas de Saúde Pública dos estados.

Quanto à Política Nacional de Recursos Humanos para o SUS, o desenvolvimento de trabaIhadores em saúde foi afirmado com sugestões à capacitação:

1) canalizar recursos financeiros para a formação dos recursos humanos para o SUS, definindo o perfil profissional apropriado a partir denecessidades concretas locai s;

2) assegurar a disponibilidade de recursos financeiros para a viabilização de programas de capacitação e qualificação permanente dos Recur- sos Humanos nos municípios, no estado e na união;

3) assegurar recursos financeiros de no mínimo $1 \%$ do orçamento da saúde para qualificar a capacitação de recursos humanos em cada esfera de governo, com prioridades e programa aprovados pelo respectivo Conselho de Saúde; 4) a União, estados e municípios devem ampliar a sua atuação na realização de cursos de especialização e aperfeiçoamento em saúde pública, descentralizados por regionais de saúde;

5) formar gerentes para o SU S com capacitação em administração pública, envolvendo gestores, assessores e dirigentes do SU S;

6) garantir a realização de programas de capacitação de gerentes para a gestão de recursos humanos e elaboração de projetos técnicos quanto aos si stemas de informação e outros.

Quanto à formação de pessoal para a saúde: 1) regulamentar 0 Art. 200 da Constituição Nacional;

2) incentivar técnica, financeira e politicamente a expansão da pós-graduação em saúde no Brasil;

3) estabelecer regras nacionais de articulação entre o M EC, as Sociedades de Especialistas e 0 CNS e passar ao SUS a decisão sobre especialidades a serem criadas ou extintas, bem como a regulamentação da diversificação dos papéis das profissões de saúde e das oportunidades formativas nos ambientes de trabalho da saúde; 4) redimensionamento do papel dos aparelhos formadores em saúde (universidades eescolas técnicas) no fortalecimento do SUS - revisão das estruturas curriculares para que se enriqueçam peIo debate da política, legislação e trabalho no SUS; 5) articulação dos a parelhos formadores com os segmentos de controle social do SU S;

6) estabeleci mento de estrutu ras acadêmicas capazes de exercer 0 assessoramento permanente às comi ssões técnicas que debatem práticas, rotinas e métodos na atenção à saúde;

7) todos os aparel hos formadores e instâncias de serviço que atuam em ensino, pesquisa edesenvolvimento científico e/ ou tecnológico devem propor sistemas de atualização do conhecimento para as diversas categorias profissionais.

Quanto à formação de profissionais, regulação e papel da universidade, foram aprovadas as seguintes recomen dações:

1) que os Consel hos de Saúde e de Educação criem critérios rígidos que regulem a criação de novas instituições formadoras, a abertura de cursos e a ampliação de vagas na área de saúde e, dentre eles, seja considerada a necessidade so- 
cial de cada região, em cumprimento à Lei no 8.080/90, Artigo 60, Parágrafo III, que diz estar no campo de atuação do SU S a ordenação da formação de recursos humanos na área de saúde. Quea aprovação se dê com base em pareceres dos Conselhos M unicipais, Estaduais e N acional de Saúde, ouvidos os respectivos Conselhos de categoria. Recomendar a partici pação da comunidade nos Consel hos Superiores das U niversidades como forma de contribuir, acompanhar e fiscalizar a formação dos profissionais de acordo com as necessidades sociais da população;

2) cumprir a resolução da $X C N S$, no que se re fere a recursos humanos, onde diz: "revisão ime diata dos currículos mínimos dos cursos de nível superior, com a participação dos gestores do SU S e Consel hos de Saúde, adequando-os às realidades locais e regionais, aos avanços tecnológicos, às necessidades epidemiológicas e às demandas quantitativas e qualitativas do SU S". Implementar novas diretrizes curriculares para o ensino médio e superior da área da saúde de modo a possibilitar modificação na formação dos profissionais de saúde, de acordo com a política proposta pelo SUS, incluindo e/ou ampliando, no currículo de cursos de formação dos profissionais da área da saúde, disciplinas sobre saúde coletiva;

3) articular mesas regionais e estaduais de discussões entre gestores, consel hos e órgãos formadores sobre a necessidade de adequar a formação profissional ao SUS, coordenada pelos Conselhos Regionais e Estadual de Saúde;

4) integrar e articular as institui ções públicas e filantrópicas de ensino com o SU S, fortalecendo as parcerias U niversidade-Soci edade de tal forma que as universidades e órgãos formadores em geral também se responsabilizem pela capacitação continuada dos profissionais de saúde após a graduação e que tenham, como parte de sua missão institucional, o aperfeiçoamento do SU S em sua região ea educação continuada dos profissionais da rede. Garantir uma escola integrada com o serviço de saúde com gestão de mocrática e horizontalizada, partilhada com o SUS, que problematize as questões de saúde de sua região, seu país e seu mundo e que atue na proposição de mudanças com e para a sociedade por meio, por exemplo, da extensão. Garantir uma escola que seja orientada para o ser humano, que produza um profissional qualificado e crítico do ponto de vista técnico-científico, humano e ético, atuante e comprometido socialmente com a luta pela saúde de seu povo. Garantir uma escola que também produza conhe- cimento ( pesquisa) para o sistema de saúde; 5) estabelecer parceria entre Conselho de Saúde, gestores e o conjunto dos órgãos formadores, para defini ção de prioridades para as demandas de cursos, tanto de graduação como de pósgraduação, para gestores e todos os trabalhadores, estendendo o processo de residência à equipe multidisciplinar. Estimular a viabilização de campos de estágio e atividades de extensão em municípios que trabal hem com diferentes formas de organização dos serviços, promoven do a discussão e proposição de uma nova lógica de atenção à saúde;

6) reorganizar os programas de residência ere gulamentar o Programa de Residência M ultiprofissional em Saúde Coletiva junto ao MEC. Os estados ea União devem utilizar residentes das universidades públicas, mediante pagamento de bolsas, nos programas de saúde, inclusive nas equipes do Programa Saúde da Família - PSF, com base na lei de Prestação do Serviço Civil; 7) efetivar a abertura de novos cursos de formação de recursos humanos para a saúde;

8) ampliar o Projeto de Profissionalização dos Trabalhadores da Área da Enfermagem - Profae para outros cidadãos.

Quanto à educação continuada foi deliberado:

1) garantir aos recursos humanos em saúde processos permanentes de educação continua$\mathrm{da}$, nas três esferas de governo, inclusi ve sobre os princípios e diretrizes do SU S e conceitos bási cos em saúde pública. Q ue todo profissional de saúde tenha treinamento de ingresso nos serviços e que os G overnos Federal, Estaduais e M unicipais assumam a sua parcela de responsabilidade com o financiamento do SUS, de forma a facilitar 0 encaminhamento da necessária qualificação dos recursos humanos para o sistema; 2) descentralizar e regionalizar as ações das Escolas de Saúde Pública para uma melhor qualificação e educação continuada dos trabalhadores da saúde.

A XI Conferência Nacional de Saúde trouxe diversos elementos para a consolidação da interface formação-gestão, como se pode notar, desde argumentos para o desenvolvimento de pessoal engajado no Controle Social em saúde (conselheiros, promotores públicos, promotores do M inistério Público, população em geral) até o fortalecimento dos princípios do SUS.

Percebe-se o depósito de expectativas para as Escolas Técnicas e Escolas de Saúde Pública dos estados. 
Voltam com força os argumentos em favor do financiamento para as ações de desenvolvimento e formação de recursos humanos no SUS. Note-se que até mesmo um percentual foi sugerido como fixação à área ( $1 \%$ do orçamento setorial da saúde) em cada esfera de governo. Retornou também a pressão pelos cursos de especialização e de aperfeiçoamento em saúde pública, a serem apoiados técnica e financeiramente pelas três esferas de governo e conduzidos de modo interiorizado regionalmente, valorizan do a cultura e necessidades locorregionais e valorizando a descentralização da gestão e a regionalização da atenção à saúde. Surge a capacitação específica em gestão de recursos humanos, que atual mente o M inistério da Saúde está atendendo em parceria com a Universidade de Brasília (UnB), e em elaboração de projetos técnicos quanto aos sistemas de informação, o que nos permite destacar a fundamental importância do Projeto RedeNacional de Informações em Saúde (RNIS), que precisaria do maciço apoio do M inistério da Saúde nas capacitações para operar os sistemas de informações.

A regulamentação do artigo 200, da Constituição Nacional, foi reiterada novamente e surgiram recomendações para inclusão na mesma: a formulação de critérios rígidos para a abertura e fechamento de cursos na área da saúde; a aprovação de abertura, fechamento e localização de cursos com base em pareceres dos Consel hos de Saúde; e a inclusão da participação social nos Consel hos Superiores das Universidades, a fim de garantir a relação entre a formação e as necessidades sociais de tratamento e cuidado em saúde.

Foi defendida a expansão da pós-graduação em saúde e, pela primeira vez, é referida a introdução das Sociedades de Especialistas no debate de regulação das especialidades e a decorrente formação de especialistas. A Conferência estimou a diversificação dos papéis das profissões em que as atuais prerrogativas venham a ser diluídas ou reguladas pela ética e não pelos códigos normativo-prescritivos e a diversificação das oportunidades formativas nos ambientes de trabal ho em saúde, abrindo-se possibilidades para as residências multiprofissionais ou interdisciplinares.

A Conferência estabeleceu a ressalva de que os órgãos formadores em saúde devam ser enriquecidos pelo debate das políticas de saúde, da legislação e do trabal ho no SUS. A amarração do controle social junto aos órgãos forma- dores foi proposta mais uma vez. Da mesma forma que em todas as Conferências citadas neste texto, a imersão dos órgãos formadores na realidade do SUS foi proposta. N essa Conferência, entretanto, aparece a proposição que - SUS deva se amparar nos pesquisadores acadêmicos para renovar protocolos técnicos e aperfeiçoar condutas profissionais da assistência à saúde. Os participantes da XI Conferência afirmaram que deve ser garantida uma escola capaz de produzir informações e conhecimentos para o sistema de saúde.

A Conferência, reconhecendo que instâncias de serviço atuam em ensino, recomenda que estas proponham sistemas de atual ização do conhecimento, levando em conta as diversas categorias profissionais.

Durante a XI Conferência, houve novamente o debate so bre os currículos de formação na área da saúde e reafirmou-se a deliberação da X Conferência de revisão do currículo mínimo com a participação dos gestores e dos Consel hos de Saúde. Em 2001, o ConseIho Nacional de Educação substituiu o conceito de "currículo mínimo" para as profissões superiores pelo conceito de "diretrizes curriculares", tendo sido aprovadas as novas diretrizes para os cursos da área da saúde que levaram em conta a LOS, o relatório final da XI Conferência Nacional de Saúde, documentos da Organização Pan-Americana da Saúde e O rganização M undial da Saúde e as recomendações da Rede Unida. 0 parecer que aprova as novas diretrizes curriculares é claro ao afirmar que o conceito de saúde da Saúde Coletiva e os princípios e diretrizes do SUS são elementos fundamentais a serem enfatizados na articulação da política de educação superior com a política de gestão da saúde.

A pareceu, nessa Conferência, mais uma alternativa de integração: a formação em saúdegestão setorial-controle social no SU S expressa como mesas regionais e estaduais de discussão a serem coordenadas por Conselhos Regionais e os Consel hos Estaduais de Saúde. Nota-se 0 esforço de comprometer a Universidade com a construção e consolidação do SU S e com a configuração de novos papéis profissionais, mais adequados às exigências sociais de qualidade da atenção em saúde. Há farta insistência na integração ensino-serviço-controle social.

0 estímulo à viabilização de campos de estágio e atividades de extensão em municípios têm sido reivindicação dos próprios acadêmi- 
cos da área da saúde. A Direção Executiva $\mathrm{Na}$ cional dos Estudantes de M edicina (Denem) vem propondo o estágio de vivência no SUS para adquirir familiarização com o trabal ho onde o SUS dá certo e pode gerar, por seu acolhimento e interesse, aprendizagem ético-profissional.

A nova atuação/novo papel dos trabalhadores de saúde passa por seus espaços de formação em serviço e as propostas sobre as residências sempre retornam, com ênfase, principalmente porque constituem formação pósgraduada na oportunidade de vivência no SUS e na Equipe de Saúde. As residências multiprofissionais ou interdisciplinares são defendidas pela reivindicação de reformulação dos programas de residência, da mesma forma que se defen de a regulamentação, junto à Secretaria de Ensino Superior do M inistério da Educação, da Residência Multiprofissional em Saúde Coletiva, capaz de absorver as residências em saúde da família e similares.

Cumpre apontar que a Conferência admite a efetivação da abertura de novos cursos de formação para a saúde e propõe a necessidade de ampliar o Programa de Profissionalização dos Trabalhadores da Área de Enfermagem (Profae) para outras categorias de trabaIhadores do ensino médio. 0 movimento da Conferência evidenciou a busca de profissionalização em outras áreas, tais como: em odontologia, com os Técnicos de Higiene Dental; em vigilância à saúde, com os Técnicos em Saúde; em administração e informação, com os Técnicos em Registros de Saúde; entre outros, além do Técnico em Enfermagem, abrangido pelo Profae.

Para afirmar a educação continuada/educação permanente em saúde, os participantes da XI Conferência Nacional de Saúde ressaltaram a necessidade de os governos Federal, Estaduais e M unicipais assumirem sua parcela de responsabilidade com a formação e desenvolvimento de trabal hadores em saúde por meio do financiamento para a qualificação de pessoal no custeio do SU S. Ficou destacada, ainda, a necessidade de descentralizar e regionalizar os processos de formação. De um lado, pela capacidade/potencialidade/opção de problematizar as questões de saúde das regiões onde se inserem os programas de ensino e, de outro lado, pelo desdobramento das Escolas de Saúde Pública às instâncias regionais de coordenação do SUS nos estados.

\section{Epílogo}

Esta compilação não se pretendeu exaustiva ou minuciosa, simplesmente pinçou o que saltava aos olhos na interface formação-gestão do SUS. Esperamos ter conseguido reunir dados para avaliar o que já foi feito e o que há por fazer em cada esfera de governo no tocanteà formação e ao desenvolvimento de trabal hadores em saúde, bem como estimular a criação de Câmaras Técnicas de Educação e D esenvolvimento Científico, junto aos Consel hos Estaduais de Saúde, junto às Escolas Técnicas eEscolas de Saúde Pública; estimular a criação de centros formadores junto às Secretarias M unicipais de Saúde; fortalecer as Escolas de Saúde Pública e pleitear a garantia de financiamento para a atribuição de ensino, pesquisa, documentação técnico-científica e extensão educativa nos âmbitos federal, estadual e municipal de saúde.

O utras recomendações importantes que saltam aos ol hos ao final deste percurso são a necessidade de criar Núcleos de Desenvolvimento e Núcleos de Administração de TrabaIhadores junto às Divisões de Recursos Humanos das Secretarias Estaduais e M unicipais de Saúde e a aproximação dos gestores com os docentes e pesquisadores universitários para a formulação de novos protocolos de atenção à saúde, que abandonem a conduta programáticonormativa para a atualização técnica e reflexiva da prática assistencial.

A pesar de discursivamente muitas propostas terem sido enfaticamente formuladas e defendidas nos vários relatórios das Conferências, muito pouco se avançou na construção de sistemas de avaliação do ensino oferecido para detectar sua adequação e adesão às necessidades dos serviços, dos usuários e do sistema de saúde, bem como seu ajustamento ao controle social no SUS e ao atendimento às necessidades de aprendizagem de seus alunos. Os sistemas nacionais gerados pela Cinaem e Rede Unida junto ao ensino de graduação ou o sistema de Acreditação Pedagógica em construção pela Fiocruz e Abrasco para a pós-graduação lato sensu e o sistema de avaliação de curso de capacitação (extensão) formulado para teste pelo IM S/UERJ consideram todos oS segmentos envolvidos com o ensino-aprendizagem e, se contarem com o apoio técnico, financeiro, operacional e político das esferas de gestão do SUS, terão potência para se atualizarem, fortalecerem e se redimensionarem pa- 
ra absorver maior diversidade de cursos e programas de formação.

A avaliação permanente e a participação efetiva do controle social junto à formação serão importantes, também, para se dimensionar a adesão dos programas e projetos aos ditames ou necessidades dos próprios usuários do SUS.

Por fim e não menos importante, convém destacar a urgência em compor as Comissões
Permanentes previstas em lei, superando os atuais modelos pontuais disseminados pelo M inistério da Saúde (que, em geral, ol ha a realidade de longe) e valorizar a descentralização da gestão em saúde, regionalizando a atenção e a formação. Estas últimas, necessariamentea serviço da primeira, possibilitarão, permanentemente, a revisão de planos e estratégias de ensino e roteiros de formação e educação continuada.

\section{Referências bibliográficas}

Brasil 1988. Constituição da República Federativa do Brasil. Senado, Brasília, DF.

Brasil 2000. Lei n. 8.080, de 19 de setembro de 1990. Dispõe sobre as condições para a promoção, proteção e recuperação da saúde, a organização e o funcionamento dos serviços correspondentes e dá outras providências. SU S é legal: legislação federal e estadual. SES/ RS, Porto Alegre, out.

Brasil 2000. Lei n. 8.142, de 28 de setembro de 1990. Dispõe sobre a participação da comunidade na gestão do Sistema Ú nico de Saúde e sobre as transferências intergovernamentais de recursos financeiros na área da saúde e dá outras providências. SUS é legal: legislação federal e estadual. SES/RS, Porto Alegre, out.

Brasil 2001. M inistério da Educação. Parecer CNE/CES n. 1.133/2001, aprovado em 07 de agosto de 2001. Diretrizes curriculares nacionais dos cursos de graduação em enfermagem, medicina e nutrição. Brasília. Disponível em: <http://www.mec. gov.br/cne/default. shtm\#Diret> Acesso em 26 de out.

Brasil 2001. M inistério da Educação. Parecer CNE/CES n. 1.210/2001, aprovado em 12 de setembro de 2001. Diretrizes curriculares nacionais dos cursos de graduação em fisioterapia, fonoaudiologia e terapia ocupacional. Brasília. Disponível em: <http://www.mec. gov.br/ cne/default.shtm\#Diret> Acesso em 26 de out.
Brasil 2001. M inistério da Educação. Curso de graduação em farmácia: proposta de diretrizes curriculares. Brasília. Disponível em: <http://www.mec.gov.br/cne/ default.shtm\#Diret> Acesso em 26 de out.

Brasil 2001. M inistério da Educação. Curso de graduação em odontologia: proposta de diretrizes curriculares. Brasília. Disponível em: <http://www.mec.gov.br/ cne/default.shtm\#师 iret> Acesso em 26 de out.

Brasil 2001. M inistério da Educação. Curso de graduação em educação física: proposta de diretrizes curriculares. Brasília. Disponível em: <http://www.mec.gov.br/ cne/default.shtm \#D iret> Acesso em 26 de out.

Conferência Nacional de Saúde, 8, 1986, Brasília. Reformulação do Sistema Nacional de Saúde. Relatório Final. M inistério da Saúde, Brasília.

Conferência Nacional de Saúde, 9, 1992, Brasília. Saúde: municipalização é o caminho. Relatório Final. M inistério da Saúde, Brasília.

Conferência Nacional de Saúde, 10, 1996, Brasília. Onde dá SUS, dá certo! Relatório Final. M inistério da Saúde Brasilia.

Conferência Nacional de Saúde, 11, 2000, Brasília. Efetivando o SU S: acesso, qualidade e humanização na atenção à saúde, com controle social. Relatório Final. Ministério da Saúde, Brasília.

Artigo apresentado em 9/4/2002 Versão final apresentada em 19/4/2002 Aprovado em 28/4/2002 